Correction

\title{
Correction: Iemma, U. Theoretical and Numerical Modeling of Acoustic Metamaterials for Aeroacoustic Applications. Aerospace 2016, 3, 15
}

\section{Umberto Iemma}

Department of Engineering, Roma Tre University, via Vito Volterra 62, Rome 00146, Italy; umberto.iemma@uniroma3.it; Tel.: +39-329-057-0839

Received: 14 December 2016; Accepted: 20 December 2016; Published: 22 December 2016

The author regrets that this paper [1] contains a typographical error in Equation (1), i.e., the equation governing the propagation of an acoustic disturbance within a metamaterial with anisotropic inertia. The correct form is shown in Table 1.

Table 1. Correct form of Equation (1).

\begin{tabular}{cc}
\hline Published Equation & Corrected Equation \\
\hline $\mathcal{B} \nabla \cdot\left(\varrho^{-1} \nabla p\right)+\ddot{p}=0$ & $\mathcal{B} \nabla \cdot\left(\varrho^{-1} \nabla p\right)-\ddot{p}=0$ \\
\hline
\end{tabular}

The error, not noticed during the proofreading process, was a simple mistype. The analytical developments and the results following Equation (1) are in no way adversely affected by this typo.

The author would like to apologize for any inconvenience caused. The manuscript will be updated and the original will remain online on the article webpage.

\section{Reference}

1. Iemma, U. Theoretical and Numerical Modeling of Acoustic Metamaterials for Aeroacoustic Applications. Aerospace 2016, 3, 15. [CrossRef]

(C) 2016 by the author; licensee MDPI, Basel, Switzerland. This article is an open access article distributed under the terms and conditions of the Creative Commons Attribution (CC-BY) license (http:/ / creativecommons.org/licenses/by/4.0/). 